\title{
DE WALTER WHITE A HEISENBERG: EL CAMINO DEL (ANTI)HÉROE EN LA SOCIEDAD DEL RIESGO
}

\section{From Walter White to Heisenberg: The (Anti)Hero's Journey in the Risk Society}

\section{De Walter White a Heisenberg: O Caminho do (Anti)Herói na Sociedade do Risco}

Delicia Aguado Peláez, Universidad del País Vasco (UPV/EHU)

deliciaaguado@gmail.com

\section{Recibido: 03 de marzo de 2016 \\ Aceptado: 11 de julio de 2016}

\section{RESUMEN}

El nuevo milenio revitaliza las tesis de Ulrich Beck (2008) y su sociedad del riesgo a través de dos grandes acontecimientos que golpean a Estados Unidos en el arranque del siglo XXI: los atentados del 11 de Septiembre $-\mathrm{y}$ sus consecuencias- y la Gran Recesión. Precisamente en este ambiente de incertidumbre se desarrolla uno de los momentos de mayor esplendor para las producciones dramáticas estadounidenses conocida como la Tercera Edad Dorada de la televisión. Este doble contexto es el punto de partida de la presente investigación que se centra en el papel de la ficción en la reproducción de la sensación de miedo. Así pues, el estudio se centra en Breaking Bad (AMC, 2008-2013), uno de los grandes éxitos de esta época de calidad e innovación.

De esta forma, y haciendo uso del análisis de contenido cualitativo, se estudia la influencia de la sociedad del riesgo a partir del impacto del miedo en la trama, prestando especial atención a la construcción del personaje principal y su consecuente evolución hacia el antiheroísmo. Una investigación que revela la importancia de la ficción a la hora de explicar y reproducir el presente ambiente de incertidumbre.

Palabras clave: Breaking Bad, ficción, (anti)héroe, series de televisión, sociedad del riesgo. 


\section{DISERTACIONES}

\section{ABSTRACT}

In the new millennium, the thesis of Ulrich Beck (2008) focused on the Risk Society are continuously revitalized, not only by the $9 / 11$ attacks and its consequences but by the economic crisis that starts seven years later in the USA. An environment strongly influenced by the uncertainty, where the so-called Third Golden Age of American Television also takes place. It is just that the bottom of this research that questions the role of fiction in reproducing the sensation of fear. For such purpose, the case study is Breaking Bad (AMC, 2008-2013). A television series which is born between these two historic moments that impacts in its plot and in its sub-genres.

In this way, the Qualitative Content Analysis allows to analyze the influence of the Risk Society on the impact of the fear in this plot, specifically the anti-heroism. A research that shows that fiction is fundamental for a better understanding of the environment of uncertainty nowadays.

Keywords: Breaking Bad, fiction, (anti)hero, television series, risk society.

\section{RESUMO}

O novo milênio revitaliza as teses de Ulrich Beck (2008) e a sua Sociedade do Risco através de dois grandes acontecimentos que atingem aos EE.UU. no arranque do século XXI: os atentados do 11 de setembro -e as suas consequências- e a Grande Recessão. Justamente neste ambiente de incerteza se desenvolve um dos momentos de maior esplendor para as produções dramáticas estadunidenses conhecida como a Terceira Idade Dourada da televisão. Este duplo contexto é o ponto de partida da presente pesquisa que se centra no rol da ficção na reprodução da sensação de medo. Assim pois, o estudo se centra em Breaking Bad (AMC, 2008-2013), um dos grandes sucessos desta época de qualidade e inovação.

Desta forma, e fazendo uso da Análise de Conteúdo Qualitativo, estuda-se a influência da Sociedade do Risco a partir do impacto do medo na trama, prestando especial atenção à construção da personagem principal e a sua consequente evolução ao anti-heroismo. Uma pesquisa que revela a importância da ficção à hora de explicar e reproduzir o presente ambiente de incerteza.

Palavras-chave: Breaking Bad, ficção, (anti)herói, séries de televisão, sociedade do risco.

\section{Introducción}

La entrada en el nuevo siglo supone un momento fundamental para la televisión estadounidense que revive el pasado esplendoroso del drama introduciéndose de lleno en la que va a ser conocida como la Tercera Edad Dorada (a partir de aquí, TED). Una época de esplendor en la que la llamada caja tonta reta en calidad e innovación a la 
gran pantalla con ficciones laureadas por público y crítica a la par (Cascajosa, 2005; Tous, 2010). Y dentro de ellas, hay que destacar aquellas producciones que recuperan el espíritu del género de la noche dejando éxitos como Los Soprano (The Sopranos, HBO, 1999-2007), The Shield (FX, 2002-2008), The Wire (HBO, 2002-2008), True Detective (HBO, 2014) o, la central en el presente texto, Breaking Bad (AMC, 2008-2013).

Merece la pena destacar la revitalización del noir si se tiene en cuenta que este género tan prototípicamente estadounidense se regocija en la proximidad al destino, a la fatalidad, al miedo y a la traición (Ebert, 1995). Pues, ya en sus orígenes, se alimenta del desencanto de la época de posguerra marcada por las heridas de la guerra y la crisis económica (Hernández, 2014). Dos factores que, en cierta manera, también caracterizan las dos primeras décadas de un nuevo milenio que entra en escena en el año 2001 con el 11 de Septiembre y que se estremece siete años más tarde con la Gran Recesión.

Es decir, Estados Unidos va a iniciar el siglo afrontando la inseguridad derivada de los atentados y cuestionándose la validez de sus instituciones para recuperar la invulnerabilidad perdida. Una búsqueda que los sumerge en la Guerra contra el Terror y sus tremendas consecuencias que van desde incursiones militares contra los países tachados como eje del mal, la creación de Guantánamo o la implantación de la Ley Patriota. Secuelas bajo el paraguas de un discurso que perfila un enemigo incierto - a golpe de estereotipos- que amenaza con un ataque inminente y que justifica la necesidad de ensalzar la seguridad en detrimento de derechos y libertades.

Un ambiente bélico que se difumina paulatinamente a lo largo de los años, especialmente con la entrada en juego de la Gran Recesión de 2008. Sin olvidar que la paranoia antiterrorista recobra fuerza puntualmente, algo que puede verse con la entrada en escena de actores como el Estado Islámico y atentados como los ocurridos en París en noviembre de 2015. Volviendo a la crisis económica, el colapso pone de nuevo en jaque otro de los indicadores de la invulnerabilidad estadounidense: el capitalismo y la sociedad de consumo del país de las oportunidades. De este modo, se vuelve a esa sensación de inseguridad y al desencanto hacia unas instituciones que, de nuevo, se desvelan deficientes para garantizar el tan enarbolado bienestar.

Todo ello remite a ese concepto que el sociólogo Ulrich Beck (2008) teoriza ya en 1986 a través de su sociedad del riesgo. Esas comunidades acechadas por la sensación de incertidumbre en la que la propia percepción de una catástrofe o un ataque se vuelve mucho más vívida que la posibilidad real de que exista. Pues con el 11S se abre "un nuevo capítulo en la sociedad del riesgo mundial. Hay que distinguir claramente entre el atentado en sí mismo y la amenaza terrorista que el mismo universaliza", siendo lo decisivo "la percepción del mismo. Lo que los hombres temen que sea real es real en sus consecuencias" (Beck, 2001). En definitiva, el miedo se convierte en una herramienta que cuestiona el funcionamiento democrático pues, para el autor, "lo que destruye las instituciones occidentales de la libertad y la democracia no es el acto terrorista, sino la escenificación global del mismo, así como las subsiguientes anticipaciones, acciones y reacciones políticas" (2008, p. 28).

De esta forma, Beck destaca la importancia del papel de los mass media en esta teatralización del miedo. Algo que analizan otras autoras como Susan Faludi que en su Pesadilla terrorista afirma cómo el 11S revive los temores olvidados de la Guerra Fría y lleva a los medios, el ocio y la publicidad a presentar la realidad post 11S a modo de "[...] una época que recuperaba los valores de los años cincuenta, la 'unidad' de la familia nuclear, la feminidad en el hogar, la masculinidad que defendía la patria” (Faludi, 2009, p. 14). O, lo que es lo mismo, a rescatar mitos heroicos viriles y protectores como la figura del vaquero. 
Ambos autores nos llevan a reflexionar sobre cómo productos culturales, como son las series de televisión, pueden ser parte de la incertidumbre. Por lo tanto, el presente texto estudia los mensajes, explícitos y latentes, que llegan desde el campo del entretenimiento, de la ficción. Pues no es casual que la propia administración Bush pensara en la industria del cine a modo de aliado contra el terror (Faludi, 2009; Huerta, 2006). En este sentido, Miguel Ángel Huerta (2006, p. 18) pone el foco sobre “[...] la importancia que tienen las películas como agentes configuradores de la percepción de la realidad, por un lado, y como documentos que nos sirven de testigos sociales y políticos, por otro". Una idea que puede ser extrapolable a las producciones de la pequeña pantalla que, en definitiva, actúan como espejos de la realidad (Dixon, 2004; Felipe y Gómez, 2011; Frezza, 2009; Grandío, 2009; Pérez Gómez, 2011...). En suma, los dramas de la TED, en general, y Breaking Bad, en particular, se alzan como objetos de estudio fundamentales para entender cómo las ficciones recrean esa incertidumbre en una sociedad marcada por el riesgo tras el 11 de Septiembre, con una consecuente reacción hacia valores conservadores (Aguado Peláez, 2014; 2015a; 2015b; 2016).

\section{Volviéndose Malo}

Ya el título de la ficción de la AMC anticipa lo que va a ser la evolución de Walter White (Bryan Cranston). Un brillante químico especializado en cristalografía que llega a sus cincuenta años combinando dos trabajos para los que está hipercualificado: profesor de química en un instituto y empleado en una empresa de lavado de coches. En definitiva, un hombre confinado a una vida humilde y rutinaria, ahogado por las responsabilidades económicas y familiares -que incluyen las necesidades de una esposa embarazada y un hijo con parálisis cerebral-. Unas preocupaciones que se acrecientan aún más cuando descubre que padece cáncer de pulmón en un estado avanzado. Sin embargo, su cotidianidad estalla cuando asiste por curiosidad a una redada con su cuñado Hank Schrader (Dean Norris), policía de la Administración para el Control de Drogas (siglas en inglés, DEA). En ella, reconoce a Jesse Pinkman (Aaron Paul), un exalumno que se gana la vida como cocinero menor de metanfetamina. Este encuentro es el punto de partida de un negocio que aúna los conocimientos prácticos del joven con la brillantez del protagonista y el inicio de uno de los mayores capos de la droga en el sur de Estados Unidos conocido bajo el pseudónimo de Heisenberg.

La creación de Vince Gilligan (Expediente X, The X-Files, Fox, 1993-2002, 2015-2016; Los Pistoleros Solitarios, The Lone Gunmen, Fox, 2001) se centra en la profundización del carácter de sus personajes principales, apegados totalmente al contexto sureño de la producción. Siempre con las drogas como telón de fondo, una temática que se aleja de esa representación moral usual en la ficción televisiva estadounidense (Raya, 2013).

Así, esta creación transmedia alcanza un extenso listado de nominaciones -230 - y premios -118 victorias ${ }^{1}-$. La audiencia también acompaña y pasa de 1,41 millones $^{2}$ en su première a 10,3 en su cierre -con más de 500000

1 Entre ellos, Emmy al mejor actor para Bryan Cranston; al/la mejor actor/actriz de reparto para Aaron Paul y Anna Gunn; y a la mejor serie dramática. O dos Globos de Oro para Cranston así como a mejor serie. Referencia: Breaking Bad, la reina de los premios. En AMCTV. Recuperado de http://www.amctv.es/blog/ breaking-bad-la-reina-de-los-premios

2 Referencia: O'Connell, Michael (2013). TV Ratings: Breaking Bad Finale Smashes Records With 10.3 Million Viewers. En The Hollywood Reporter. Recuperado de http://www.hollywoodreporter.com/live-feed/

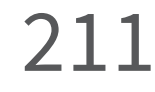


descargas durante las doce horas posteriores a su emisión en los Estados Unidos 3 - En resumen, la elección de este serial se basa en que, como se ha podido ver, es una de las producciones de éxito de la TED que, además, se desarrolla justamente en un contexto de alto interés, pues su año de nacimiento -2008- permite observar el impacto de los dos factores de incertidumbre anteriormente citados: el ambiente (pos)bélico y el impacto de la crisis económica. Hay que añadir que el drama de la AMC tiene influencia indirecta de dos subgéneros fundamentales para entender esta nueva época: el western ${ }^{4}$ y el (neo)noir ${ }^{5}$.

\section{Metodología}

El objetivo principal de la presente investigación se centra en analizar, dentro de los citados paraguas contextuales -el Post $11 \mathrm{~S}$ y la Gran Recesión-, una de las más distinguidas narraciones de la TED: Breaking Bad. Por tanto, partiendo de este caso de estudio, se busca detectar aquellos mensajes que, de forma explícita o latente, hagan referencia a ideas sociopolíticas, especialmente aquellas referidas a la sociedad del riesgo. De esta forma, los objetivos específicos son: (1) Examinar aquellas temáticas que hagan referencia a la incertidumbre desde un discurso ligado al miedo - ¿qué temas recurrentes se encuentran?, ¿cómo se representan?, ¿cómo influye el Post 11S en la narración?, ¿y la crisis económica? -; (2) Analizar el impacto de la incertidumbre en la representación de la sociedad y de sus liderazgos - ¿quién es el líder?, ¿en qué sociedad se desenvuelve?, ¿corresponde al dibujo de héroe clásico?, ¿influye en la actuación de Walter?-.

Así pues, se parte de tres grandes hipótesis de investigación: H1) "El Post 11S tiene una influencia directa en Breaking Bad a través de una trama marcada por el miedo y el conservadurismo". H2) "La crisis económica se cuela en Breaking Bad tanto en la representación del ambiente económico y social, como en la forma de desenvolverse del protagonista". H3) "La sociedad del riesgo abre la puerta al liderazgo de un antihéroe capaz de traspasar cualquier límite para sobreponerse a la incertidumbre".

Con este fin se hace uso del análisis de contenido, una técnica que permite detectar "la emergencia de aquel sentido latente que procede de las prácticas sociales y cognitivas que instrumentalmente recurren a la comunicación para facilitar la interacción que subyace a los actos comunicativos concretos y subtiende la superficie material del texto" (Piñuel, 2002, p. 4). En otras palabras, conocer los mensajes explícitos y latentes que se encuentran y relacionarlos con su contexto haciendo uso de un enfoque cualitativo al entender que, como explica José Ignacio Ruiz Olabuénaga (2012, p. 233): "La flexibilidad, la adaptabilidad, la singularidad concreta, la proximidad, el pluriplanteamiento de los que hacen gala los métodos cualitativos son, todavía, más adecuados para el análisis de contenido".

tv-ratings-breaking-bad-finale-639093

3 Referencia: Efe (2013). Breaking Bad, un final con récord de audiencia. En La Vanguardia. Recuperado de http://www.lavanguardia.com/television/series/20130930/54390220469/breaking-bad-final-record-audiencia.html

4 El propio Gilligan reconoce que es un "western post-moderno". Referencia: Mano a mano con el creador de Breaking Bad. En AMCTV. Recuperado de http://www.amctv.la/blog/mano-a-mano-con-el-creador-debreaking-bad-vince-gilligan-parte-2.

5 Aunque no cumple con todas las características de las producciones (neo)noir, se puede ver cierta influencia del género en torno a la decadencia sistémica. 
Específicamente, se toman como unidades de análisis los 62 episodios de Breaking Bad, pues el estudio de sus cinco temporadas permite ir más allá de una fotografía fija y estudiar la evolución, especialmente del personaje principal, en torno a dos grandes dimensiones ${ }^{6}$ vinculadas al contexto sociopolítico: la cultura del miedo y la representación de una sociedad conservadora ${ }^{8}$.

Dentro de esta segunda tiene mucha importancia la construcción de los personajes principales, en general, y del protagonista, en particular. Así, se realiza una primitiva fotografía de su perfil con las principales características personales -edad, estado civil, etnia, orientación sexual, procedencia, religión-, profesionales -formación, rango profesional-y económicas - orígenes y clase-, para pasar a profundizar en sus rasgos más relevantes atendiendo a sus atributos físicos, psicológicos y sus habilidades. Además, dentro de la categoría liderazgo, y para conocer la evolución del protagonista, se hace uso de los esquemas referentes al camino del héroe clásico propuestos por los mitólogos Christopher Vogler $(2002)^{9}$, Joseph Campbell $(1972)^{10}$ y Vladímir Propp $(1981)^{11}$.

\section{Resultados}

\section{El ambiente sin salida: Barrotes sistémicos}

Frente a series donde la construcción del espacio sin salida proviene de elementos mágicos o de la sensación de un ataque inminente (Aguado Peláez, 2016), en Breaking Bad los primeros barrotes se construyen a través de tres alusiones a la realidad socioeconómica, a fallos del sistema capitalista, como son:

1. El deterioro de las condiciones laborales: Walter imparte clases en un instituto local que complementa con un segundo empleo no cualificado. Algo que pone de manifiesto su falta de realización personal derivada del nulo reconocimiento social y la escasa remuneración de los profesionales de la enseñanza en Estados Unidos.

2. La ausencia de Estado de Bienestar: Walter padece una enfermedad cuyo tratamiento no es cubierto por su seguro médico. Y, con ello, no puede afrontar su cura sin, al menos, dinamitar el futuro bienestar familiar.

6 Por motivos de espacio, no se pueden desarrollar más en detalle en el presente texto, una versión más amplia se puede encontrar en Aguado Peláez, 2016.

7 Construida a través de las categorías: Ambiente sin Salida -cómo se dibuja el espacio sin salida-, Otredad -cómo se representa el enemigo-y Violencia -quién o cómo se utiliza y, especialmente, cómo se justifica su uso-.

8 Construida a través de las categorías: Liderazgo - quién es el líder, cómo lidera-, Alteridad -ausencia o presencia de sujetos subalternos y su dibujo-y Representación de las Mujeres -especialmente atendiendo a la división de espacios público/privado señalada por los feminismos-.

9 Y su análisis de arquetipos: héroe, mentor, guardián del umbral, heraldo, figura cambiante, sombra y embaucador.

10 Atendiendo a las 16 etapas del monomito repartidas en tres grandes fases: la salida, la iniciación y el retorno.

11 Que define siete perfiles fundamentales en el viaje del héroe: el héroe, la princesa, el antagonista, el ordenante, el donante, el ayudante y el falso héroe. 
3. La marginalidad de los suburbios: a través de personajes secundarios como Andrea Cantillo (Emily Rios) ${ }^{12}$ se muestra cómo una parte de la ciudad se enfanga entre droga, pobreza y violencia. Algo que pone de manifiesto no solo la diferencia de clases sino también la propia división respecto a etnia y raza -blancos vs. Latinos-.

De tal forma, este bosquejo bebe del contexto de crisis económica que se ceba con las llamadas clases medias estadounidenses y que dinamita la sociedad del bienestar de la que disfruta parte de la población acomodada que, además, no puede mirar al Estado como facilitador de una salida. En este sentido, se puede entender a modo de una "metáfora de los tiempos que nos vienen, [...] con el vertiginoso desmontaje de las esferas de protección social que hoy está teniendo lugar entre nosotros" (Villota, 2012, p. 78).

Sin embargo, el dibujo noir de un sistema fallido se entremezcla con la influencia del western llevando al protagonista hacia un arquetipo de cowboy posmoderno. Así, Walter es capaz de controlar la situación sin mirar hacia el Estado. Él mismo aprovecha su brillantez en el campo de la química para introducirse en ese mundo del cristal azul que hace que aumenten vertiginosamente sus ingresos y su autorealización. Es decir, este serial pone el foco en el individualismo extremo donde las decisiones personales son las únicas que importan -tanto en problema como solución ${ }^{13}-$, con lo que la competitividad y las habilidades pueden siempre enderezar la situación que se describe de forma aislada y privada. En otras palabras, el desarrollo de la trama rehúye cualquier crítica estructural al sistema capitalista o al modelo social estadounidense pues, como señala Iván de los Ríos (2013, p. 30), su creador "ha diseñado un juguete magistral de considerable potencial crítico, estético y narrativo y que, después, sigilosamente ha preferido pasar de largo".

Un segundo nivel de encierro proviene justamente de la única institución que se representa como fundamental: la familia. Pues, pese a que este padre adora a los suyos y busca lo mejor para ellos, también está constreñido en ese exceso de ataduras sociales que exige el papel de patriarca en las sociedades actuales. Un ahogo que se representa fundamentalmente con la figura de su esposa Skyler White (Anna Gunn) - a la que Fernando Menéndez (2014, p. 84) define como "una mujer aparentemente dulce pero con evidentes dotes de mando; que manipula y controla por completo a su marido" - y su cuñado Hank - que cuestiona continuamente su virilidad y su falta de acción-. En suma, otros barrotes que magnifican esa sensación de mediocridad y rutina bajo la represión de su verdadero yo. En esta ocasión, la liberación de estas cadenas está relacionada con la asunción del papel de vaquero, ese mito heroico tan conectado con el sentir del Post 11S (Faludi, 2009). Y como gran metáfora aparecen los desiertos de Alburquerque (Nuevo México) donde las limitaciones del Estado y las extralimitaciones de la

12 La joven aún llora la pérdida de su hermano menor, Tomás, quien, a sus 11 años, se ve envuelto en una pandilla de narcotraficantes de la zona -colaborando en la venta de narcóticos e incluso asesinando-. Una vida ligada a la violencia que va a acabar de forma trágica cuando es ejecutado por un ajuste de cuentas.

13 Y, así, se culpa a Walter porque tuvo la capacidad de triunfar años atrás pero desaprovecha la ocasión y también se ve como reparador porque es lo suficientemente competente como para salir de esa situación gracias a sus propias habilidades. Lo mismo ocurre con Andrea, causante en tanto a drogadicta, capaz de reparar la situación económica familiar cuando entabla la relación con Jesse -aunque, en esta ocasión, la posición es más de objeto que de sujeto, pues la serie está muy influenciada por estereotipos generalizados (Aguado Peláez, 2015b)-.

\section{4}


familia desaparecen al cruzar la línea entre urbe y páramo donde el hombre queda "expuesto, arrojado fuera de las 'esferas de protección', en ese no-lugar [...] donde acaba la ciudad, y en el que por tanto ya no hay sociedad" (Villota, 2012, p. 72).

Finalmente, el último nivel de encierro deviene de su propia incursión empresarial. El mundo de las drogas engulle paulatinamente a los cocineros hasta que el sentimiento carcelario domina sus vidas tanto de forma metafórica - temiendo por sus vidas y la de sus seres queridos-como real - presos primero de los laboratorios de Gustavo Fring (Giancarlo Esposito) y, más tarde, Jesse repite la experiencia con mexicanos y nazis-. Un ambiente sin salida en el que tiene mucha importancia la construcción del antihéroe de la que se hablará más adelante.

\section{Otredad: El enemigo en casa}

Si la primera categoría se adentra en la construcción de un espacio carcelario, la segunda se detiene a analizar la introducción en la trama del enemigo, del otro. Algo vital entendiendo que la oposición maniquea de buenos contra malos es un mecanismo ideológico fundamental, especialmente en momentos de incertidumbre, al reforzar la identidad del nosotros frente al diferente, el hostil.

Así las cosas, lo primero es preguntarse ¿quién configura el nosotros en esta ficción? Como no podía ser de otra manera, el personaje que lleva este peso es Walter. En un primer momento, se busca que el espectador se identifique con ese ciudadano medio atrapado en su propia rutina, sin embargo, paulatinamente se le pide que empatice con un capo de la droga. Y lo cierto es que cuando se descubre el genio oculto bajo el disfraz de mediocridad, no es de extrañar que el público no solo le perdone el desvío hacía la villanía, sino que sea justamente su antiheroísmo el principal engranaje de simpatía de la audiencia con el sujeto. Como explica Joaquín Marín Montín (2014, p. 150), se da una "edipización" del personaje o "impulso hostil hacia la ley paterna, que se ve frenado por lo que en psicoanálisis se conoce como el 'complejo de castración'". Es así que, al desatar a su Edipo, se "permite al espectador identificarse con el protagonista de manera incondicional".

Por extensión, ese nosotros incluye el entorno de Walter, pues, aunque la familia encierre al albuquerqueño, también es la salvaguarda de su moral -especialmente Skyler y Jesse-. De hecho, incluso Hank entra en este bando. Ya que, pese a que el agente de la DEA siga incesantemente el rastro de su cuñado, nunca llega a ser perfilado como el otro. Todo lo contrario, el agente representa al propio sistema americano que garantiza la seguridad. De modo que se esboza como fanfarrón y más limitado, pero también es íntegro y honrado. Es decir, conserva cierta conexión con el público, algo que lo convierte en antagonista pero no en villano.

Hasta la temporada final, la otredad recae íntegramente en el vecino sureño, rivales hispanos altamente estereotipados que testean el talante del químico. En suma, a más inmersión del protagonista en el mundo del narcotráfico, mayor el nivel de sofisticación de sus contrincantes. De los primeros camellos menores que mueven su negocio con torpeza a un Fring capaz de tutear la brillantez y el maquiavelismo de Heisenberg. A este respecto, Iván de los Ríos (2013, pp. 32-33) explica que Gilligan opta por esa "fascinación que produce el más simple de los mecanismos narrativos: el de la contraposición estructural entre dos instancias antagónicas". Una herramienta ampliamente usada desde Occidente que "si bien facilita la digestión conceptual y el impacto comercial, no admite más que diferencias previsibles entre pares inmutables, eliminando toda modulación problemática y toda gradación sutil”.

\section{5}


Sin embargo, el personaje de Walter evoluciona tanto a lo largo de las temporadas que va a ir girando hacia la otredad. De tal forma, del enfrentamiento con Fring se desenmascara a un hombre capaz de cualquier cosa con tal de lograr sus objetivos. Ebrio de poder, termina enfrentándose a los suyos. Esto es, dentro del miedo propio de las ficciones tras el 11S, "en este caso son Skyler y el resto de la familia de White los que descubrirán aterrados que el mal ha conseguido filtrarse de forma subrepticia hasta el corazón de su hogar" (Errasti, 2014, p. 22). Una situación que se resume en esta conversación entre ambos (406: Cornered) ${ }^{14}$ :

-Skyler: Walt, please, let's both of us stop trying to justify this whole thing and admit you're in danger...

-Walter: Who are you talking to right now? Who is it you think you see? Do you know how much I make a year? I mean, even if I told you, you wouldn't believe it. Do you know what would happen if I suddenly decided to stop going into work? A business big enough that it could be listed on the NASDAQ goes belly up. Disappears! It ceases to exist without me. No, you clearly don't know who you're talking to, so let me clue you in. I am not in danger, Skyler. I am the danger. A guy opens his door and gets shot and you think that of me? No. I am the one who knocks!

De esta forma, cuanto más profunda es la transformación de Walter en un vaquero del siglo XXI, más se aleja Skyler de él, hasta el punto de apartar a su familia de su esposo bajo la premisa de que "Someone has to protect this family from the man who protects this family" (406 Cornered) ${ }^{15} \mathrm{O}$, incluso, de desear que regrese el cáncer (504: Fifty-One $)^{16}$. Este deseo se corresponde con la propia decadencia de Heisenberg, totalmente ciego por su ego que llega al límite al cerrar un trato con una banda de neonazis. Un hecho que arrastra a la perdición al protagonista y a los suyos hasta suponer su ocaso: despojado de su poder y su fortuna, en soledad y totalmente consumido por el cáncer. Precisamente, este declive va a ser aprovechado por los creadores para ofrecer un ápice de redención al químico.

Así pues, el último foco de otredad se centra en un grupo neonazi y su socia, Lydia Rodarte-Qualyle (Laura Fraser). En esta ocasión, se aleja de la alteridad mexicana y se pone el foco en la decadencia del sistema estadounidense tan propia del género noir. Además, estos antagonistas sirven para enfatizar esa montaña rusa donde está subido el químico: pues si los primitivos matones significaban los primeros pasos de Walter y la brillantez de Fring mira a la cara al gran Heisenberg, este clan tosco y mediocre simboliza el deterioro del personaje así como una oportunidad para que Walter lleve a cabo su venganza, desenrede ciertas acciones y, con ello, tenga su gran final.

14 Traducción: -Skyler: Walt, por favor, vamos a dejar los dos de intentar justificar todo esto y admitir que estás en peligro -WALTER: ¿Con quién estás hablando ahora? ¿A quién te crees que tienes delante? ¿Sabes cuánto gano al año? Si te lo dijera no te lo creerías. ¿Sabes lo que pasaría si decidiera dejar de ir a trabajar? ¡Un negocio tan grande que podría estar en el NASDAQ se hundiría! ¡Desaparecería! Dejaría de existir sin mí. No, está claro que no sabes quién soy. Te diré algo: Yo no estoy en peligro, Skyler. Yo soy el peligro. Un tipo abre su puerta y le disparan. ¿Tú crees que sería a mí? No. Yo soy el tío que llama.

15 Traducción: "Alguien tiene que proteger a esta familia del hombre que protege a esta familia".

16 -Skyler (S): All I can do is wait. That's it, that's the only good option. Hold on. Bide my time. And wait. Walter (W): Wait for what? What are you waiting for? -S: For the cancer to come back. Traducción: -S: Lo único que puedo hacer es esperar. Es todo, es la única opción: esperar que pase el tiempo y esperar. -W: ¿Esperar qué? ¿Qué estas esperando? -S: Que el cáncer se reproduzca. 


\section{El uso de la violencia: La heinserbergación de Walter}

El tratamiento de la violencia en Breaking Bad es fundamental pues se dibuja consustancial al mundo de la droga. Su bosquejo posee los ecos de los subgéneros del drama dominantes en la trama. De este modo, las muertes caen en esa añoranza estética donde la repulsión se entremezcla con las cuidadas salpicaduras de sangre a cámara. Aunque lo más importante para la construcción de la sociedad del riesgo es su uso. Pues los dos cocineros deben abrazarla para poder desenvolverse en su profesión, aunque con consecuencias muy diferentes para Jesse y Walter. De esta forma, el primero, un joven que tontea con las drogas y su venta, resulta absolutamente carcomido por la culpa; mientras que el segundo es devorado por la alargada sombra de Heisenberg, su alter ego.

Y es que la producción se centra justamente en la heinserbergación de Walter. Cuanto más se acomoda en el mundo del narcotráfico, más abandona su ética y, con ello, más fácil le resulta realizar todo tipo de actos que van desde la manipulación, al envenenamiento - de un niño- o al asesinato múltiple. Actos que justifica en torno a la necesidad extrema de supervivencia - o tú o yo- amparado en la propia crueldad del sistema en el que se ve inmerso. Paulatinamente, la narración pone contra las cuerdas a un espectador que entiende que Walter -o Heisenberg-debe hacer lo que hace para proteger a su familia y su negocio, sin darse cuenta de que pronto deberá salvarlos de sí mismo. En definitiva, es tanto engranaje de incertidumbre como herramienta para que el vaquero consiga sus fines.

\section{El liderazgo: El camino del vaquero}

La biografía de Walter es la del viaje de un hombre común atado a los corsés sociales que amarran su masculinidad hacia la liberación de un vaquero de moral gris adaptado a los tiempos que corren. Algo que solo se entiende desde ese "contexto de incertidumbre de una crisis económica global en una década afectada por los atentados del 11 de Septiembre, [que] puede propiciar en la ficción la presencia de ciertos comportamientos humanos que modifican las conductas heroicas para hacer frente a situaciones extremas" (Marín, 2014, p. 145).

En sus inicios, aunque Walter encaja en el esquema del llamado sujeto político normativo androcéntrico ${ }^{17}$, también se aleja del arquetipo de tipo duro hardboiled ${ }^{18} \tan$ asociado a la masculinidad patriarcal que reniega de los afectos y sensibilidades. De hecho, se perfila como lo contrario: cariñoso, ético, sociable, resiliente y totalmente alejado de la acción. Sin embargo, a lo largo de las cinco temporadas, el químico se reinventa a sí mismo y pasa de ser un hombre afectivo, altruista, cuidador y sacrificado a un Heisenberg caprichoso, cruel, despreocupado, cerebral e indócil. De ser adaptable, dialogante, humanitario, igualitario, manso, pacifista y respetuoso evoluciona hacia un ser agresivo, beligerante, estricto, implacable, posesivo y tirano. Y es de especial interés cómo pierde su ética y desarrolla una profunda moral gris - deshonesto, maquiavélico, pesimista y trascendental-. Una transformación siempre marcada por el ingenio del protagonista y cierto aire de locura que lo convierte en un ejemplo paradigmático del arquetipo hardboiled.

17 Desde los feminismos, se describe este arquetipo dominante como varón, blanco, heterosexual, en edad productiva, sin discapacidades que, además, pertenece a las clases medias/altas tanto culturales como económicas (Amorós, 1985; Pateman, 1995, entre otras).

18 Subgénero de la novela negra bañado por sexo y violencia. Aquí se hace referencia a ese protagonista dibujado desde el estereotipo de tipo duro y moral gris, tan típico de estas creaciones. 
En resumen, cuanto más se introduce en el poder y la violencia, más aumenta su sensación de poder y reconocimiento. Así, el albuquerqueño se libera de las ataduras de la emotividad ahondando en los clichés más viriles de la masculinidad normativa. Toda una metáfora de la reacción de la que hablaba Faludi (2009) en la que parte de los líderes de opinión culpan a la que consideran la feminización de la nación como responsable de la vulnerabilidad del territorio estadounidense y reclaman una vuelta a los mitos heroicos del siglo pasado. Pues en una sociedad donde sus ciudadanos se desenvuelven en el riesgo, no hay sitio para las emociones.

En definitiva, Walter se convierte en Heisenberg y, con ello, cae continuamente en clichés de villano. Y, sin embargo, este es justamente el motor del vínculo con el público "en un modelo 'perverso' de recepción, a través del cual los procesos de proyección e identificación imaginarias [...] contradicen los tradicionales valores heroicos, cuando nos representan justamente prototipos de abierta maldad" (Fernández Pichel, 2013, p. 105). Pese a ello, atendiendo a los análisis de Campbell (1972), Propp (1981) y Vogler (2002) se puede decir que el protagonista realiza, a grandes rasgos, el camino del héroe, aunque con matices.

De hecho, en su periplo se va topando con los arquetipos fundamentales de este recorrido. Así, Walter cuenta con un compañero - Jesse-; un amor como objetivo - Skyler-; ayudantes - Gale Botticher (David Costabile), Todd Alquist (Jesse Plemons)-; mentores -Mike Ehrmantraut (Jonathan Banks), Saul Goodman (Bob Odenkirk)-, o con sus propios bufones - de nuevo, Gale y Saul-. Incluso con su antagonista -Hank-y varios villanos con los que ir rivalizando -Tuco Salamanca (Raymond Cruz), Fring, Jack Welker (Michael Bomen)-.

Y, con ellos, el protagonista va cumpliendo las tres etapas prototípicas del viaje épico. Por un lado, la salida coincide con la primera entrega: Walter descubre su cáncer y debe buscar una salida económica. Como en los clásicos, sus dudas y el miedo a introducirse en un mundo peligroso que desconoce son esenciales en este primer momento. Además, si bien es cierto que se aleja de elementos sobrenaturales, su conocimiento y la creación de su cristal azul de extrema pureza actúan tal ese tótem mágico que ayuda al héroe a iniciar su periplo.

A partir de ahí, su iniciación se corresponde con las primeras pruebas que testean su inteligencia y habilidades y lo introducen en el uso de la violencia. En este viaje, las tentaciones tienen forma de dinero y, especialmente, de poder. Walter cae entre ellas y paulatinamente pasa a transformarse en Heisenberg o, lo que es lo mismo, en villano. Aquí se incluye una variante fundamental de los clásicos al entrar en acción la figura del antihéroe. Un personaje más mundano adaptado a los tiempos modernos, a esas sociedades de incertidumbre y desengaño.

La introducción de Heisenberg conlleva éxito pero también la destrucción de su familia y, con ello, la última de las etapas: el regreso. La entrega final muestra a un Walter totalmente degradado que se arrastra a Albuquerque en busca de redención. Algo que encuentra, en cierta manera, con su sacrificio final.

En suma, Breaking Bad muestra ese camino del antihéroe que se dibuja gracias a un adalid disfrazado de vaquero y a un entorno cargado del desengaño sistémico (neo)noir (Aguado Peláez y Martínez García, 2016). Un arquetipo que va a estar muy presente en una TED marcada por el riesgo (Aguado Peláez, 2016).

\section{La alteridad: La dictadura de la normatividad}

La figura del sujeto político normativo es imperante en toda la trama. Como se verá más adelante, las mujeres tienen una presencia muy acotada. Además, entre los protagonistas no hay prácticamente representación de personajes de edad avanzada, pertenecientes al colectivo LGBTI o con diversidad funcional. No más allá del caso 
de Walter White Jr. (R. J. Mitte) con parálisis cerebral - que sirve para aumentar la presión del químico de cara al sustento familiar-o ciertas dependencias puntuales - el accidente de Hank o el cáncer del propio Walter-. Tan solo la etnia rompe esta normatividad y, lo más interesante, es que lo hace a golpe de estereotipo y jugando con la diferencia.

Así, frente a los dos cocineros protagonistas o del policía que persigue a Walter -hombres angloparlantes, blancos y estadounidenses que además encajan dentro de la normatividad masculina-, el espectador ve pasar por la pantalla infinidad de rivales hispanos, poniendo el énfasis en esa diferencia lingüística y racial. Pues los latinos están constantemente relacionados con el consumo, la venta y la producción de droga y, con ello, con la corrupción, la decadencia y, especialmente, la violencia. En definitiva, el sabor a western de Breaking Bad coloca a Walter como el vaquero que, en vez de lidiar frente a bandidos y nativos americanos, lo hace con capos de la droga e hispanos. Y, con ello, su imagen -especialmente México- se reduce al universo del narcotráfico. Es decir, se hace uso del "imaginario de la Frontera [...] reproduce estereotipos nacionales y raciales consolidados en toda una tradición de ficciones literarias y/o cinematográficas", algo ligado al "origen de un mal atávico, plagado de terrores y supersticiones lejos de toda racionalidad, un espacio decididamente monstruoso" (Fernández Pichel, 2013, p. 113).

A este respecto, hay que destacar que el albuquerqueño es tan brillante que no tarda en captar la atención de los propios cárteles mexicanos hasta tal punto que los Cuates de Sinaloa le van a dedicar su propio narcocorrido ${ }^{19}$ : The Ballad of Heisenberg (207: Negro y Azul). En uno de sus fragmentos cantan en castellano: "La fama de Heisenberg ya llegó hasta Michoacán. [...] Ahora sí le quedó bien a Nuevo México el nombre. A México se parece en tanta droga que esconde, solo que hay un capo gringo, por Heisenberg lo conocen". En su estudio sobre narcocorridos, Felipe Oliver (2014, p. 108) destaca la importancia de la introducción de este género en una superproducción anglosajona. Pues, a diferencia de los locales cantares tradicionales, narra las aventuras ficticias de un mafioso estadounidense que se enfrenta a la red mexicana. Es, en definitiva, una forma de otorgar un marcado capital simbólico al protagonista al mitificar sus andaduras (Oliver, 2014, p. 108): "un capo norteamericano (poco importa que se trate de un personaje ficticio) es elevado a dimensiones míticas a partir de instrumentos emanados de la cultura popular mexicana".

\section{Las mujeres: Damas tras el varón}

De abogados a camellos, de policías a capos, el drama de la AMC está dominado por los hombres. Tan solo seis papeles femeninos ocupan cierta importancia en la trama y cuatro de ellas son compañeras sentimentales de los protagonistas y sus personajes sirven básicamente para construir al varón. Es el caso de Skyler, Marie Schrader (Betsy Brandt), Jane Margolis (Krysten Ritter), y Andrea.

La de mayor peso en la trama es justamente Skyler, la par femenina de Walter. Desde el inicio, juega a ser el ama de casa prototípica ligada a la esfera privada -amor romántico, cuidados, maternidad, sexo-, que rara vez ocupa el espacio público - productivo-y, cuando lo hace, resulta fallida. Sin embargo, y como ya se ha dicho, es fundamental para la construcción y evolución del personaje:

19 Una variedad de corrido mexicano que narra la vida de personajes o eventos relacionados con el narcotráfico.

\section{9}


a. Punto de partida: Castración. Skyler simboliza las ataduras sociales que caen sobre Walter.

b. Desarrollo (I): Liberación. Walter entiende que la decisión de introducirse -y mantenerse- en el mundo de la droga se justifica en el papel de sustentador familiar, el que ha de garantizar el bienestar de su esposa e hijos, incapaz de entender que es cuestión de ego y poder. Además, su desconexión enfatiza su independencia.

c. Desarrollo (II): Moral gris. Skyler intenta frenar la imparable pérdida de ética del protagonista y hacerlo regresar al mundo de las emociones. Algo en lo que resulta fallida -incluso lo impulsa a lo contrario-.

d. Cierre: Decadencia y redención. La separación definitiva de la pareja coincide con el declive de Walter, un personaje apesadumbrado y en soledad que busca perdón. Y, en este camino, la figura de su expareja va a ser, de nuevo, fundamental. Es, en definitiva, un papel que está siempre bajo la sombra del varón y anclado al ambiente privado.

Por otro lado, tan solo dos mujeres ocupan la esfera pública: Wendy (Julia Minesci) y Lydia. La primera es una prostituta adicta a las drogas cuya aparición, aunque anecdótica, es de colaboradora con los cocineros, siempre bajo cierto toque cómico. La segunda es una ejecutiva que se introduce en el mundo de las drogas. Pese a que este último es el personaje femenino más ligado al poder, hay que destacar que está construido como una parodia de la femme fatale. En otras palabras, sigue el arquetipo (neo)noir en torno a la búsqueda de poder o en el uso de la manipulación sexual pero se complementa con la construcción de una mujer cobarde, errática e inepta, totalmente fuera de lugar. Resumiendo, es una villana esperpéntica que se enfrenta a un Heisenberg acabado. Como recuerda David Caldevilla (2010, p. 76) en la ficción televisiva tiene tanto peso la construcción nuclear de la familia que "una mujer con iniciativa parece suponer una amenaza para el hombre de la casa. Por tanto, la iniciativa, en general, tiende a eliminarse de los personajes femeninos, ya que suele verse con recelo en la sociedad, y viceversa". Es decir, "o bien evitan a las mujeres con iniciativa o bien la acentúan de sobremanera, cargando su actitud con connotaciones negativas".

\section{Conclusiones}

Como resultado, al recuperar las tres hipótesis de partida se puede afirmar que Breaking Bad está marcada por ese ambiente de riesgo que bebe tanto de los ecos del 11S como de la Gran Recesión. Pues la trama se construye en base a la incertidumbre que conforma un ambiente sin salida a través de barrotes simbólicos que hacen referencia a la inseguridad económica y personal. Una inseguridad que alude, principalmente, a la necesidad de supervivencia por encima de derechos, igualdad o libertades.

Por un lado, la crisis se deja sentir mediante el género de la noche e impacta directamente en la recreación de un sistema ahogado por unas instituciones decadentes. Instituciones bosquejadas desde la corrupción y/o la incompetencia que no solo son incapaces de garantizar el bienestar de sus ciudadanos sino que son la causa de su malestar. Ejemplo de ello, la falta de cobertura social o la precariedad laboral; la problemática de la drogadicción o el olvido de los suburbios; la violencia ligada a los cárteles de la droga o la de las bandas de neonazis; el narcotráfico bajo la máscara de un empresario filántropo o la dejadez de las diferentes policías locales. Escenarios sombríos donde la única salida parece estar alejada de la idea de comunidad en pro de ese individualismo tan enraizado en la sociedad estadounidense. 
Es así que Walter se convierte en causa y solución a su problema. Causa porque dejó pasar toda una carrera brillante por apostar por una vida monótona, tranquila y, en cierto modo, mediocre. Solución dado que no tarda en demostrar ser todo un superviviente capaz de solventar las problemáticas de un ciudadano aislado gracias a su propio ingenio y a su valía -afrontar los costes del tratamiento o sustentar a los suyos, primero, desenvolverse en el mundo del narcotráfico, después-. Sin embargo, la supervivencia tiene un precio y el protagonista debe abandonar las ataduras que lo ligan a su vida común $-y$, con ello, al mundo de las emociones y, en consecuencia, de la familia - para abrazar su condición de antihéroe -la violencia y, con ello, un espacio público y de reconocimiento-. Y, así, la narración justifica ese volviéndose malo que ya advierte el propio título del serial de un Heisenberg siempre amparado en la necesidad de hacer frente a la incertidumbre en el país de las oportunidades.

Esta reflexión nos lleva al siguiente género que inunda la trama: el western. Porque Walter -Heisenberg-se convierte en un vaquero del siglo XXI. Jugando con escenarios desérticos como propio símbolo del límite de la sociedad, este hombre da rienda suelta progresivamente a una moral gris que le permite realizar todo tipo de actos. Actos siempre justificados por una causa que considera justa, su familia, incapaz de ver que está siendo totalmente devorado por su propio ego. De esta forma, el protagonista va quemando etapas de su camino de (anti) héroe mientras se enfrenta a sus antítesis: narcos provenientes mayoritariamente del mundo hispanoamericano. Pues esta producción es un relato que pone sobre la mesa la importancia de la otredad en cuanto a motor de incertidumbre y coloca a un otro esbozado cual enemigo incierto - casi invisible- que amenaza la seguridad del personaje principal y la de los suyos.

En este caso, la alteridad se representa a golpe de estereotipos que beben del imaginario de frontera a través de clivajes como clase, etnia/raza y lengua. Esto nos lleva a afirmar que la narración reproduce una sociedad dominada por una normatividad imperante que excluye y/o caricaturiza hasta el esperpento a los sujetos subalternos, como es el caso de los latinos o de las mujeres.

A este respecto, cabe destacar que los personajes femeninos son escasos, altamente estereotipados y, en gran medida, su único papel es ayudar a construir a los protagonistas varones. Siempre bajo su sombra, están relegadas al ámbito privado y, cuando intentan saltar hacia el espacio público, se muestran fallidas. Gran ejemplo de ello son Skyler y Lydia. La primera un ama de casa obsesionada por amarrar las emociones de su esposo y que fracasa - arrastrando a su marido- en sus intentos profesionales. La segunda una esperpéntica femme fatale que intenta liderar un entramado de droga pero que es infinitamente inferior a Walter. Este dibujo entre inexistencia y error de las mujeres públicas se corresponde con la reacción conservadora de la que habla Faludi (2009) en una sociedad que revive la figura del vaquero con la esperanza de poder superar la brecha de vulnerabilidad que se abre después de ese 11 de Septiembre. Un mito heroico que realza una virilidad protectora que exacerba el prototipo más tradicional de masculinidad frente a una feminidad recluida en los cuidados y el hogar.

En definitiva, Breaking Bad continúa con los ecos de ese martes en el que las tesis de Beck (2001) sobre la sociedad del riesgo se hacen más vívidas que nunca y cuya incertidumbre se mantiene viva entre miedos a atentados y a derrumbes financieros. Pues Walter White, o más bien Heisenberg, se presenta a modo de un antihéroe que puede ser la esperanza de unos espectadores atrapados en una sociedad decadente marcada por la inseguridad, que mira hacia sus instituciones con recelo y que solo confían en las acciones individuales como vía de escape. Un vaquero oscuro para una época sin salida. 


\section{Referencias ${ }^{20}$}

1. Aguado Peláez, Delicia (2014). Imaginario postapocalíptico en las series de televisión norteamericanas tras el 11S: Análisis de The Walking Dead (AMC, 2010-). En Espacios de Comunicación. Actas del IV Congreso Internacional de la Asociación Española de Investigación de la Comunicación, AE-IC. Bilbao. Recuperado de http://www.aeic2014bilbao.org/download/aeic2014bilbao_comunicaciones.pdf

2. Aguado Peláez, Delicia (2015a). La sociedad del riesgo en la ficción televisiva tras el 11 de Septiembre. El caso de Homeland (Showtime, 2011) y The Walking Dead (AMC, 2010). En Carlos Lozano Ascencio, La construcción del acontecer de riesgos y de catástrofes. Cuadernos Artesanos de Comunicación, 82. La Laguna (Tenerife): Latina. Recuperado de http://www.cuadernosartesanos.org/abscac82.html

3. Aguado Peláez, Delicia (2015b). La dominación simbólica sigue siendo cosa de hombres. Análisis de la supremacía masculina en Breaking Bad, Hijos de la Anarquía y The Walking Dead. En Actas XII Congreso AECPA, ¿Dónde está hoy el poder? Donostia: UPV/EHU. Recuperado de http://www.aecpa.es/congresos/ XII-congreso/paper.php?paper=1448

4. Aguado Peláez, Delicia (2016). Cuando el miedo invade la ficción. Análisis de Perdidos (Lost, 2004-2010) y de otros quality dramas de la era Post 11S (Tesis doctoral inédita). Universidad del País Vasco/Euskal Herriko Unibertsitatea (pendiente de publicar).

5. Aguado Peláez, Delicia y Martínez García, Patricia (2016). La tv-noir de la Tercera Edad Dorada desde una perspectiva de género. Análisis de Mob City, True Detective y Fargo. En El género negro. De la marginalidad a la normalización. Santiago de Compostela: Andavira.

6. Amorós, Celia (1985). Hacia una crítica de la razón patriarcal. Madrid: Anthropos Editorial del Hombre.

7. Beck, Ulrich (2001). El mundo después del 11-S. En El País. Recuperado de http://elpais.com/diario/2001/10/19/opinion/1003442407_850215.html

8. Beck, Ulrich (2008). La sociedad del riesgo mundial. En búsqueda de la seguridad perdida. Barcelona: Paidós.

9. Campbell, Joseph (1972). El héroe de las mil caras. Psicoanálisis del mito. México: Fondo de Cultura Económica.

10. Caldevilla, David (2010). Estereotipos femeninos en series de televisión. En Chasqui, (111), 73-78. Recuperado de <http://repositorio.flacsoandes.edu.ec/handle/10469/5598\#.VZwjzEYYNvA> Cascajosa, Concepción (2005). Prime Tim., Las mejores series de TV americanas, de CSI a Los Soprano. Madrid: Calamar Ediciones.

11. Cascajosa, Concepción (2007). La caja lista: Televisión norteamericana de culto. Barcelona: Laertes.

12. Cobo Durán, Sergio y Hernández-Santolalla, Víctor (2014). Breaking Bad. 530 gramos (de papel) para serieadictos no rehabilitados. Madrid: Errata Naturae.

20 Esta investigación tiene un compromiso con la perspectiva de género. Así, siguiendo las recomendaciones de la Guía para un uso no sexista del lenguaje y de las imágenes de la Universidad del País Vasco (UPV/EHU), se aboga por la inclusión de los nombres de pila completos en las referencias bibliográficas como forma de promocionar la visibilidad de las mujeres. 
13. Dixon, Winston (2004): Film and Television after 9/11. Carbonade: Southern Illinois University Press.

14. Ebert, Roger (1995). A Guide to Film Noir Genre. En Robert Ebert Journal (blog). Recuperado de http:// www.rogerebert.com/rogers-journal/a-guide-to-film-noir-genre.

15. Errasti, José (2014). ¡Está dentro y nos va a matar a todos! En Eduardo Galán (Ed.), Todavía voy por la primera temporada. España: Léeme Libros.

16. Felipe, Fernando de y Gómez, Iván (2011). Ficciones colaterales. Las huellas del 11-S en las series made in USA. Barcelona: UOCpress.

17. Fernández Pichel, Samuel Neftalí (2013). Amado Monstruo. Lo heroico y lo monstruoso en Walter White. En Sergio Cobo Durán y Víctor Hernández-Santolalla, Breaking Bad. 530 gramos (de papel) para serieadictos no rehabilitados. Madrid: Errata Naturae.

18. Frezza, Gino (2009). Guerras y postguerras. La visión política del futuro en la ciencia ficción de los cómics, películas y series contemporáneas. En Formats. Revista de Comunicació Audiovisual, (5). Recuperado de http://www.upf.edu/materials/depeca/formats/pdf_/art_dos_esp1.pdf

19. Faludi, Susan (2009). La pesadilla terrorista. Miedo y fantasía en Estados Unidos después del 11-S. Barcelona: Anagrama.

20. Galán, Eduardo (Ed.) (2014). Todavía voy por la primera temporada. España: Léeme Libros.

21. Grandío, María del Mar y Muruzábal, Amaya (2009). La representación de la guerra en la ficción televisiva norteamericana. En Mediaciones Sociales, (5). Recuperado de http://revistas.ucm.es/index.php/MESO/ article/view/MESO0909220063A/21182

22. Huerta, Miguel Ángel (2006): Celuloide en llamas. El cine estadounidense tras el 11-S. Madrid: Notorious

23. Hernández Pérez, Elisa (2014). Bron/Broen: pervivencia televisiva del noir clásico en el contexto contemporáneo. En Faro Fractal, 2, (20). Recuperado de http://www.revistafaro.cl/index.php/Faro/article/ view/349/240

24. De los Ríos, Iván (2013). Adversus White: Tres objeciones de amor y una ovación desesperada. En Sergio Cobo Durán y Víctor Hernández-Santolalla, Breaking Bad. 530 gramos (de papel) para serieadictos no rehabilitados. Madrid: Errata Naturae.

25. Marín, Joaquín (2014). Más allá de la metamorfosis química. En Juan Vargas-Iglesias (Coord.), Los héroes están muertos. Heroísmo y villanía en la televisión en el nuevo milenio. Palma de Mallorca: Dolmen Editorial.

26. Martínez de Albeniz, Iñaki y Moreno, Carmelo (Eds.) (2012). De Anatomía de Grey $a$ The Wire. Madrid: Los libros de la Catarata.

27. Menéndez, Fernando (2014). Breaking Bad: informe para una serie. En Eduardo Galán (Ed.). Todavía voy por la primera temporada. España: Léeme Libros.

28. Oliver, Felipe (2014). Narcocorridos atípicos en la música norteña contemporánea. Ejemplos y reflexiones. En Caracol, (8). Recuperado de http://www.revistas.usp.br/caracol/article/view/98959/97486

29. Pateman, Carole (1995). El contrato sexual. Barcelona: Anthropos.

30. Pérez-Gómez, Miguel Ángel (Coord.) (2011). Previously on: Estudios interdisciplinarios sobre la ficción televisiva en la Tercera Edad Dorada de la Televisión. Sevilla: Biblioteca de la Facultad de Comunicación de la Universidad de Sevilla. Recuperado de http://fama2.us.es/fco/frame/previouslyon.pdf 
31. Piñuel, José Luis (2002). Epistemología, metodología y técnicas del análisis de contenido. En Estudios de sociolingüística: Linguas, sociedades e culturas, 3 (1). Recuperado de https://www.ucm.es/data/cont/ docs/268-2013-07-29-Pinuel_Raigada_AnalisisContenido_2002_EstudiosSociolinguisticaUVigo.pdf

32. Propp, Vladímir (1981). Morfología del cuento. Madrid: Editorial Fundamentos.

33. Raya Bravo, Irene (2013). Story Matters Here. Breaking Bad en el contexto de producción de la AMC en la era de la Quality Television. En Sergio Cobo Durán y Víctor Hernández-Santolalla, Breaking Bad. 530 gramos (de papel) para serieadictos no rehabilitados. Madrid: Errata Naturae.

34. Ruiz Olabuénaga, José Ignacio (2012). Metodología de la investigación cualitativa. Bilbao: Universidad de Deusto.

35. Vargas-Iglesias, Juan J. (Coord.) (2014). Los héroes están muertos. Heroísmo y villanía en la televisión del nuevo milenio. Palma de Mallorca: Dolmen.

36. Villota, Gabriel (2012). Breaking Bad. ¿Hay vida comunitaria en el afuera de la ciudad? En Iñaki Martínez de Albeniz y Carmelo Moreno (Eds.), De Anatomía de Grey $a$ The Wire. Madrid: Los libros de la Catarata.

37. Vogler, Christopher (2002). El viaje del escritor. Las estructuras míticas para escritores, guionistas, dramaturgos y novelistas. Teià (Barcelona): Robinbook. 